\title{
Assessment tools for risky behaviors: Psychology and health
}

\section{Sabrina Castellano, Giuseppe Alessio Platania, Simone Varrasi, Concetta Pirrone, Santo Di Nuovo}

\author{
Department of Educational Sciences, University of Catania, Catania, Italy
}

\section{Editorial}

Thanks to the work of Division 38 of the American Psychological Association, Health Psychology has been defined in its methods and objectives. The biomedical vision of pathophysiological processes, indeed, could not take into account the complex relationship between medical conditions, psychological variables and contextual factors. Being healthy was not a matter of "silence of the organs" (Leriche, as cited by Canguilhem, 1991, p. 91) anymore, but encompassed representations, values, motivations and participation in social life. World Health Organization (WHO) still adopts this vision, referred to as biopsychosocial perspective. According to it, health disciplines should focus not only on treatment, but also on prevention, education, monitoring and social policy.

With this aim, Health Psychology has developed a variety of assessment approaches for detecting and measuring healthy and risky behaviors. According to Trimpop (1994, p. 9), risky behaviors are "any consciously, or non-consciously controlled behavior with a perceived uncertainty about its outcome, and/or about its possible benefits, or costs for the physical, economic or psycho-social wellbeing of oneself or others". From this point of view, the Theory of Reasoned Action represents an interesting perspective (Fishbein \& Ajzen, 1975). It explains that in order to trigger an action, what plays a fundamental role is the intention, that is the motivation that drives the individual to choose to adopt one behavior rather than another. The intention, in turn, is closely linked to the attitudes, the subjective rules and the perception of control that the subject has with respect to behavior. Thus, the interaction of these three variables allows understanding the cause that leads individuals to

Correspondence: Giuseppe Alessio Platania, Department of Educational Sciences, University of Catania, Palazzo Ingrassia Via Biblioteca, 4, 95124, Catania, Italy.

E-mail: alessio.platania@outlook.it

Key words: Assessment, risky behaviors, diagnosis.

Contributions: All the authors contributed equally.

Conflict of interest: The authors declare no conflict of interest.

Received for publication: 8 July 2020.

Accepted for publication: 11 July 2020

This work is licensed under a Creative Commons AttributionNonCommercial 4.0 International License (CC BY-NC 4.0).

(C) Copyright: the Author(s), 2020

Licensee PAGEPress, Italy

Health Psychology Research 2020; 8:9235

doi:10.4081/hpr.2020.9235 act in a certain way.

In this regard we present some of the main tools that can help health experts and, more specifically, psychologists to define risky behaviors and the motivations connected to them.

Many data are usually collected with self-reports tools. It is the case, for instance, of questionnaires, diaries and surveys filled in by the person whose behavior is the target of the assessment. Other strategies consist in the professional observation of the target behaviors, supported by specific grids and a precise time sampling. Two or more observers can be implied to assure reliability of results. Psychometric tests are useful to compare a subject's scores to the norm, thanks to the validation previously conducted on a representative sample. Finally, new technology and medical analyses can be implied in the assessment to strengthen data collection (Luszczynska \& Hagger, 2016; Caponnetto \& Milazzo, 2019).

Examples of self-reports tools include Timeline follow-back (TLFB) self-reports (Menon, 1994), useful to obtain information about the consumption of drugs, marijuana and cigarettes from 7 days to 12 months, in one or more subjects. A calendar is used to structure the report, whereas birthday dates, holidays and news events are used to improve the techniques for recalling the autobiographical memory. TLFB can be used in clinical contexts where changes in drug, marijuana and cigarette levels are to be estimated, as well as to monitor and/or evaluate the results of a specific treatment (Sobell et al., 1996).

Direct observation is a representative example of observation tool (Simmons \& Reuben, 2000). Direct observation is carried out by a specially trained expert, who must be present at the moment when an individual, whose behavior is to be observed, acts in a specific way (for example, when s/he eats food, or when $\mathrm{s} /$ he drinks alcoholic beverages). The goal is to record, for a limited period of time, such behavior deemed harmful or at risk. Most of the times, direct observation is used to study the behavior of an elderly person hospitalized in an assisted living facility, a child or a disabled person (Simmons \& Reuben, 2000).

As regards psychometric tools, a fundamental test in this area is the Symptom Checklist (SCL-90-R) (Derogatis, 2011). It is a self-report questionnaire characterized by 90 items, which investigates any disturbances presented by the subject over the past week. Answers are given on a 4 -interval Likert scale $(0=$ not at all; $4=$ very much). The results allow to know the progress of the subject in reference to the following 9 different symptoms: somatization; obsession-compulsion; interpersonal hypersensitivity; depression; anxiety; hostility; phobic anxiety; paranoid ideation; psychoticism. In addition, there are other 7 items ("other") that measure appetite and sleep disturbances. Tree global indices complete the assessment: Global Severity Index (GSI), which measures the intensity of any discomfort; the Positive Symptom Total (PST), which summarizes the number of symptoms of a subject, and the Positive Symptom Distress Index (PSDI), which assesses the response style (Derogatis, 2011).

Among sensor-based techniques of assessment, pedometers can 
be used to measure physical activity. Number of steps, covered distance and amount of energy are registered for a variety of objectives, such as for tracking sedentary behavior and enhancing physical activity in patients with type 2 diabetes (De Greef, Deforche, Tudor-Locke, \& De Bourdeaudhuij, 2010). Cameras can be used to record target behaviors and assess their frequency, for instance food intake in the treatment of obesity (Kong \& Tan, 2012). Biochemicals and sensor-based tools, instead, have been implied to detect carbon monoxide in the breath to manage smoking behavior (Morabia, Bernstein, Curtin, \& Berode, 2001), or residues of drugs in body fluids (Brener, Billy, \& Grady, 2003), or nutrients in the blood to check dietary balance (Natarajan et al., 2006).

In conclusion, it is possible to affirm that Health Psychology is fundamental in the detection of risky behaviors, in the primary and/or secondary prevention, as well as to monitor the treatment and verify its effectiveness. In this regard, the assessment tools are an important resource to health experts.

\section{References}

Brener, N.D., Billy, J.O., \& Grady, W.R. (2003). Assessment of factors affecting the validity of self-reported health-risk behavior among adolescents: evidence from the scientific literature. The Journal of adolescent health: official publication of the Society for Adolescent Medicine, 33 (6), 436-457. https://doi.org/10.1016/s1054-139x(03)00052-1

Caponnetto, P., \& Milazzo, M. (2019). Cyber Health Psychology: The use of new technologies at the service of psychologycal well being and health empowerment. Health psychology research, 7(2), 8559. https://doi.org/10.4081/hpr.2019.8559

De Greef, K., Deforche, B., Tudor-Locke, C., \& De Bourdeaudhuij, I. (2010). A cognitive-behavioural pedometer-based group intervention on physical activity and sedentary behaviour in individuals with type 2 diabetes. Health education research, 25(5), 724-736. https://doi.org/10.1093/her/cyq017

Derogatis, L. (2011). Manuale di somministrazione e scoring. Adattamento italiano di SCL-90-R (I. Sarno, E. Preti, A. Prunas, \& F. Madeddu, a cura di). Firenze: Giunti, Organizzazioni Speciali.

Fishbein, M., \& Ajzen, I. (1975). Belief, Attitude, Intention, and Behavior: An Introduction to Theory and Research. Reading,
MA: Addison-Wesley.

Kong, F., \& Tan, J. (2012). DietCam: Automatic dietary assessment with mobile camera phones. Pervasive and Mobile Computing, 8 (1), 147-163. https://doi.org/10.1016/j.pmcj.2011.07.003

Leriche, R. quoted in G. Canguilhem (1991). On the Normal and the Pathological. New York: Zone Books.

Luszczynska, A., \& Hagger, M. (2016). Health Behavior. In Y. Benyamini, M. Johnston \& E. C. Karademas (Eds.) Assessment in Health Psychology. Hogrefe \& Huber Pub.

Menon, G. (1994). Judgments of behavioral frequencies: Memory search and retrieval strategies. In N. Schwarts \& S. Sudman (Eds.) Autobiographical memory and the validity of the retrospective reports (pp. 161-172). New York, NY: Springer.

Morabia, A., Bernstein, M. S., Curtin, F., \& Berode, M. (2001). Validation of self-reported smoking status by simultaneous measurement of carbon monoxide and salivary thiocyanate. Preventive Medicine, $\quad 32,88$. http://doi.org/10.1006/pmed.2000.0779

Ortis, A., Caponnetto, P., Polosa, R., Urso, S., \& Battiato, S. (2020). A Report on Smoking Detection and Quitting Technologies. International journal of environmental research and public health, 17(7), 2614. https://doi.org/10.3390/ijerph17072614

Natarajan, L., Flatt, S.W., Sun, X., Gamst, A.C., Major, J.M., Rock, C.L., Al-Delaimy, W., Thomson, C.A., Newman, V.A., Pierce, J.P., \& Women's Healthy Eating and Living Study Group (2006). Validity and systematic error in measuring carotenoid consumption with dietary self-report instruments. American journal of epidemiology, 163(8), 770-778. https://doi.org/10.1093/aje/kwj082

Simmons, S.F., \& Reuben, D. (2000). Nutritional Intake Monitoring for Nursing Home Residents: A Comparison of Staff Documentation, Direct Observation, and Photography Methods. Journal of the American Geriatrics Society, 48 (2), 209-213. https://doi.org/10.1111/j.1532-5415.2000.tb03914.x

Sobell, L.C., Sobell, M.B., Buchan, G., Cleland, P.A., Fedoroff, I., \& Leo, G.I. (1996). The reliability of the Timeline Followback method applied to drug, cigarette, and cannabis use. Paper presented at the 30th Annual Meeting of the Association for Advancement of Behavior Therapy, New York, NY, November 1996.

Trimpop, R.M. (1994). The Psychology of Risk Taking Behaviour. North Holland, Amsterdam, The Nederlands. 